\title{
Knowledge and practices on malaria prevention in two rural communities in Wakiso District, Uganda
}

\author{
David Musoke ${ }^{1}$, George Karani², John C Ssempebwa ${ }^{1}$, Samuel Etajak ${ }^{1}$, David Guwatudde ${ }^{3}$, Miph B Musoke
}

1. Department of Disease Control and Environmental Health, Makerere

University College of Health Sciences, School of Public Health, Kampala, Uganda

2. Cardiff School of Health Sciences, Cardiff Metropolitan University, UK

3. Department of Epidemiology and Biostatistics, Makerere University College of

Health Sciences, School of Public Health, Kampala, Uganda

4. School of Sciences, Nkumba University, Uganda

\begin{abstract}
Background: Malaria is the leading cause of morbidity and mortality in Uganda particularly among children under 5 years of age.

Objectives: The study assessed the knowledge and practices on malaria prevention in 2 rural communities in Wakiso District, Uganda with emphasis on the various prevention methods.

Methods: The study was a cross-sectional survey carried out among 376 households using both quantitative and qualitative methods. Log-binomial regression, chi square and Spearman's rank order correlation were used to test for associations.

Results: The majority of participants $(64.6 \%)$ had low knowledge on malaria prevention methods, with untreated mosquito nets $(81.7 \%)$, mosquito coils $(36.9 \%)$ and insecticide treated nets $(29.6 \%)$ being the most known methods. Knowledge on malaria prevention methods was associated with age $(\chi 2=32.1 ; \mathrm{p}<0.01)$, employment status $(\chi 2=18.1 ; \mathrm{p}<0.01)$, education $\left(\chi^{2}=20.3 ; \mathrm{p}=0.01\right)$, income $\left(\chi^{2}=14.5 ; \mathrm{p}=0.01\right)$ and having heard a malaria message in the previous 12 months $(\chi 2$ $=92.3 ; \mathrm{p}<0.01)$. Households that had at least one mosquito net were $45.5 \%$ and net ownership increased with household income. Only $0.5 \%$ of the houses had undergone indoor residual spraying in the previous 12 months, while $2.1 \%$ had complete mosquito proofing in windows and ventilators to prevent mosquito entry.

Conclusion: There is potential to improve practices on malaria prevention by targeting other methods beyond mosquito nets such as installing proofing in windows and ventilators. The integrated approach to malaria prevention which advocates the use of several malaria prevention methods in a holistic manner should be explored for this purpose.
\end{abstract}

Keywords: Malaria, prevention, knowledge, practices, integrated approach, Uganda

DOI: http://dx.doi.org/10.4314/ahs.v15i2.13

\section{Introduction}

Malaria is a significant public health challenge particularly in sub-Saharan Africa. In 2012, there were an estimated 207 million cases of the disease worldwide with most $(80 \%)$ being in Africa ${ }^{1}$. In Uganda, malaria

\author{
Corresponding author: \\ David Musoke \\ Department of Disease Control \\ and Environmental Health, School \\ of Public Health, Makerere University \\ College of Health Sciences \\ P. O. Box 7072, Kampala, Uganda \\ Tel: +256414543872 \\ Fax: +256414531807 \\ Email: dmusoke@musph.ac.ug
}

is the leading cause of morbidity and mortality especially among children under five years of age. An estimated 8-13 million cases occur per year and account for approximately $30-50 \%$ of outpatient care, $15-20 \%$ of health facility admissions and 9-14\% of inpatient deaths in the country ${ }^{2}$. Uganda ranks fourth among the highest malaria burdened countries in the WHO African region based on the estimated number of cases $^{3}$. In addition to its impact on health, the burden of malaria in the country has also social and economic dimensions. The social dimension includes hindrances to usual social participation due to the disease. The economic costs can be direct including seeking treatment or preventive measures, or indirect ones such as low productivity due to absenteeism from school / work and time lost caring for the sick ${ }^{4}$.

The current global malaria control core interventions 
are use of long lasting insecticidal nets (LLINs), indoor residual spraying (IRS), preventive chemotherapy in cluding intermittent preventive treatment among pregnant women, and prompt diagnosis and treatment ${ }^{1}$. These strategies are also being used in the control of malaria in Uganda ${ }^{2}$. The use of insecticide treated nets (ITNs) has significantly increased in recent years. Households that own at least one ITN are estimated at $60 \%$, while $45 \%$ of Ugandans have access to an ITN ${ }^{5}$. The Ministry of Health has previously provided free ITNs especially for children under five years of age and pregnant women with over three million nets being distributed since $2006^{6}$.

However, the disease still causes a great burden to the country's health system ${ }^{7}$. In addition to the use of ITNs and IRS, other measures can be implemented at household level to reduce mosquitoes that transmit the disease. These measures include installing screens in windows, ventilators, and eaves to prevent entry of mosquitoes; eliminating mosquito breeding sites notably stagnant water for instance through filling with soil; larviciding; and reducing vegetation near houses where mosquitoes habour ${ }^{8,9,10}$. Several challenges have been identified while seeking health care for malaria (and other illnesses) in Uganda. The challenges include travelling long distances to health facilities and regular stock out of drugs ${ }^{11}$.

The success of malaria control interventions require high utilisation of global and national interventions ${ }^{12}$ However, inadequate knowledge is a main challenge for the appropriate use of these interventions at individual and community levels ${ }^{13}$. Indeed, knowledge on malaria prevention methods is likely to influence practices by households in the control of the disease. It is therefore important to establish communities' knowledge and practices on malaria control particularly in rural areas which face a high burden of the disease ${ }^{2,14}$

This study assessed the knowledge and practices on malaria prevention in two rural communities in Wakiso district, Uganda with emphasis on the various prevention strategies that can be used. The study was carried out as a baseline survey before implementation of a pilot project that promoted the integrated approach to malaria prevention which advocates the use of several malaria prevention methods in a holistic manner at households ${ }^{15}$. nets, ITNs, mosquito coils, spraying houses with insecticides, taking preventive medicine, mosquito repellents and draining mosquito breeding sites. Knowledge on malaria prevention was therefore assessed by the number of malaria prevention methods mentioned by the participants, with each method contributing a score of 1 to form an assessment score. Participants with an assessment score of 0 were categorized as having no knowledge; 1 - 3 low knowledge; 4 - 6 medium knowledge and above 6 high knowledge.

The knowledge assessment scores were converted into percentages using the number of participants in each category as the numerator and total number of participants involved in the study as the denominator. Practices on malaria prevention were assessed by the individual methods being used by households to prevent malaria and related risk factors which were obtained from the questionnaire and observational checklist. The practices and risk factors obtained from the questionnaire were use of mosquito nets (treated and untreated), IRS and time of closing windows while those observed were mosquito proofing in windows and ventilators, presence of stagnant water and presence of overgrown vegetation. Key informants provided in-depth data on community knowledge and practices on malaria prevention which was used to supplement the quantitative data.

\section{Data analysis}

Quantitative data was entered in SPSS version 17 and transferred to STATA version 12 statistical softwar for analysis. At univariate level, categorical variables were summarized using frequencies and percentages while continuous ones are presented using mean and inter-quartile range. The chi-square test was used to identify potential factors that may be associated with knowledge on malaria prevention methods among the participants. Since use of LLINs is the most advocated method for malaria prevention globally and nationally, factors associated with ownership of mosquito nets, and the relationship between number of nets owned with household size were identified. For bivariate and multivariate analysis, log-binomial regression mode as used to estimate the crude and adjusted prevalence the ratios at $95 \%$ confidence intervals for the factor associated with ownership of mosquito nets. Covariates that were significant at $\mathrm{p}<0.1$ at bivariate level and those with biological plausibility were included in multivariable analysis. Spearman's rank order correlation was un to assess the relationship between number of mosquito nets in households and household size.

From the transcribed qualitative data, summaries were generated highlighting the emerging issues. Coding of the data was then done for all the transcribed work. The coded data was then used to identify the key emerging themes from the qualitative data which was guided by the summaries initially generated. After the themes were identified, the transcribed data was reread to ensure that all coded data was correctly assigned to respective themes.

\section{Ethical consideration}

Approval to conduct the research was obtained from the Makerere University School of Public Health Higher Degrees, Research and Ethics Committee. The study was also registered at the Uganda National Council for Science and Technology. The local leaders of the study area were duly informed about the study and permission obtained from them before collecting data. Written informed consent was obtained from participants before they took part in the study.

\section{Results}

ocio-demographic characteristics of participants Majority of participants had gone to school, with $45.2 \%$ having attained primary school education as their highest level of education and 39.1\% with secondary school education. Nearly half of the participants $(49.2 \%)$ had an average household monthly income between $20-60$ US dollars (USD) with only 5.9\% earning more than 100 USD. Over half of the participants (50.5\%) had household size between $4-6$ members while most were female $(67.6 \%)$. The largest number of participants $(33.8 \%)$ was in the age category of $25-34$ years (Table 1). of malaria, and their health seeking behaviour when child under 5 years of age in their household had maaria. The question regarding knowledge on malaria prevention methods had 7 possible responses plus any other mentioned by the participants. The 7 method regarding knowledge were use of untreated mosquito 
Table 1 Socio-demographic characteristics of participants

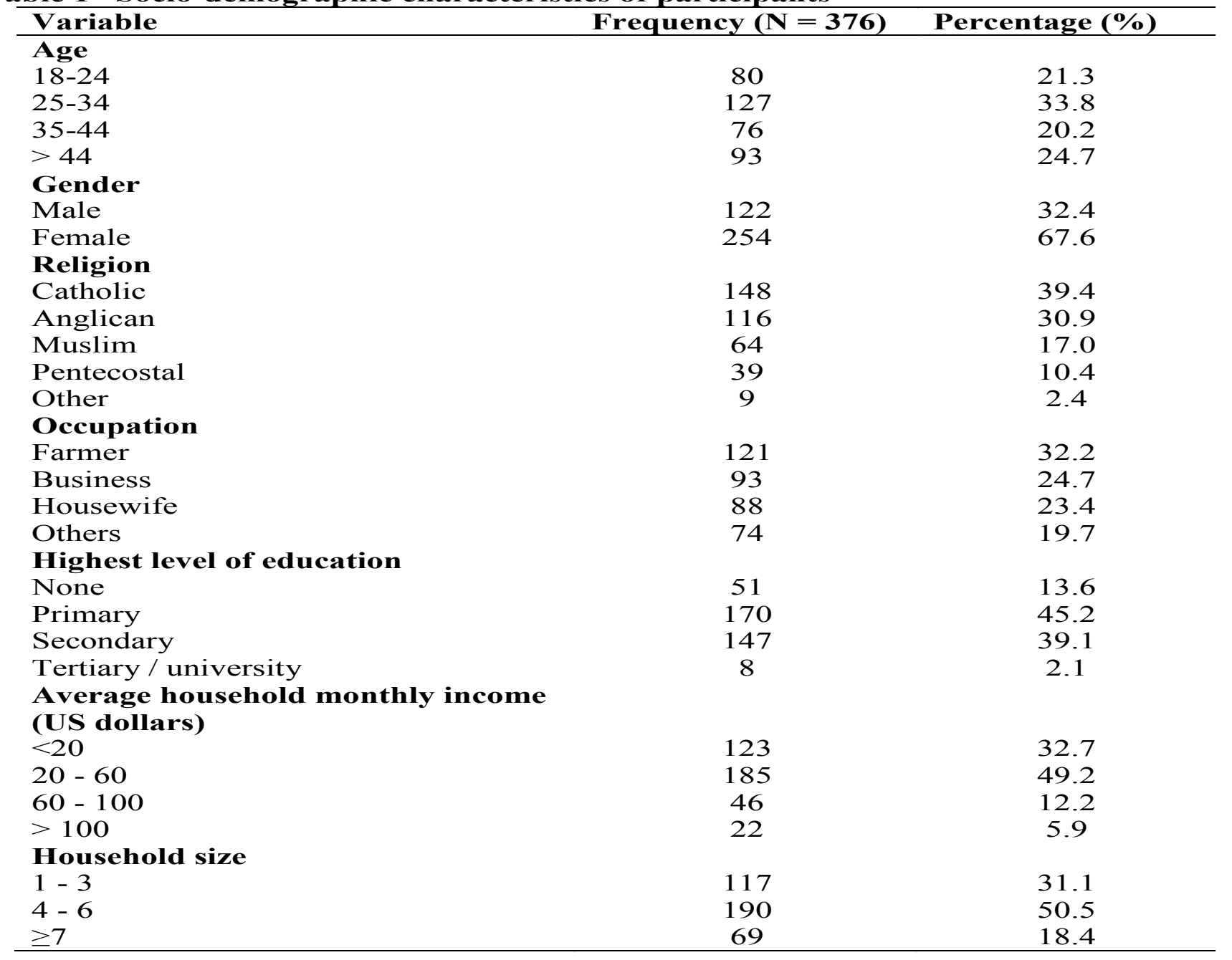

\section{Knowledge on malaria prevention}

Majority of participants $(89.6 \%)$ were aware of malar-

others were health facilities $(9.5 \%)$, community leaders

er, other transmission routes of the disease given were Majority of participants $(67.6 \%)$ were aware of ways cold / changing weather $(11.7 \%)$, drinking un-boiled to avoid getting malaria. The most prominent methods water $(10.1 \%)$ and eating maize $(6.9 \%)$. Over half of were: sleeping under mosquito nets including untreatthe participants $(56.1 \%)$ had heard or seen messages ed $(81.7 \%)$ and insecticide treated ones $(29.6 \%)$, using about malaria in the previous 12 months. The main mosquito coils (36.9\%) and spraying houses with insecsource of malaria information was radio $(70.6 \%)$ while ticides (17.3\%) (Figure 1).

\section{Figure 1 Knowledge on individual malaria prevention methods}

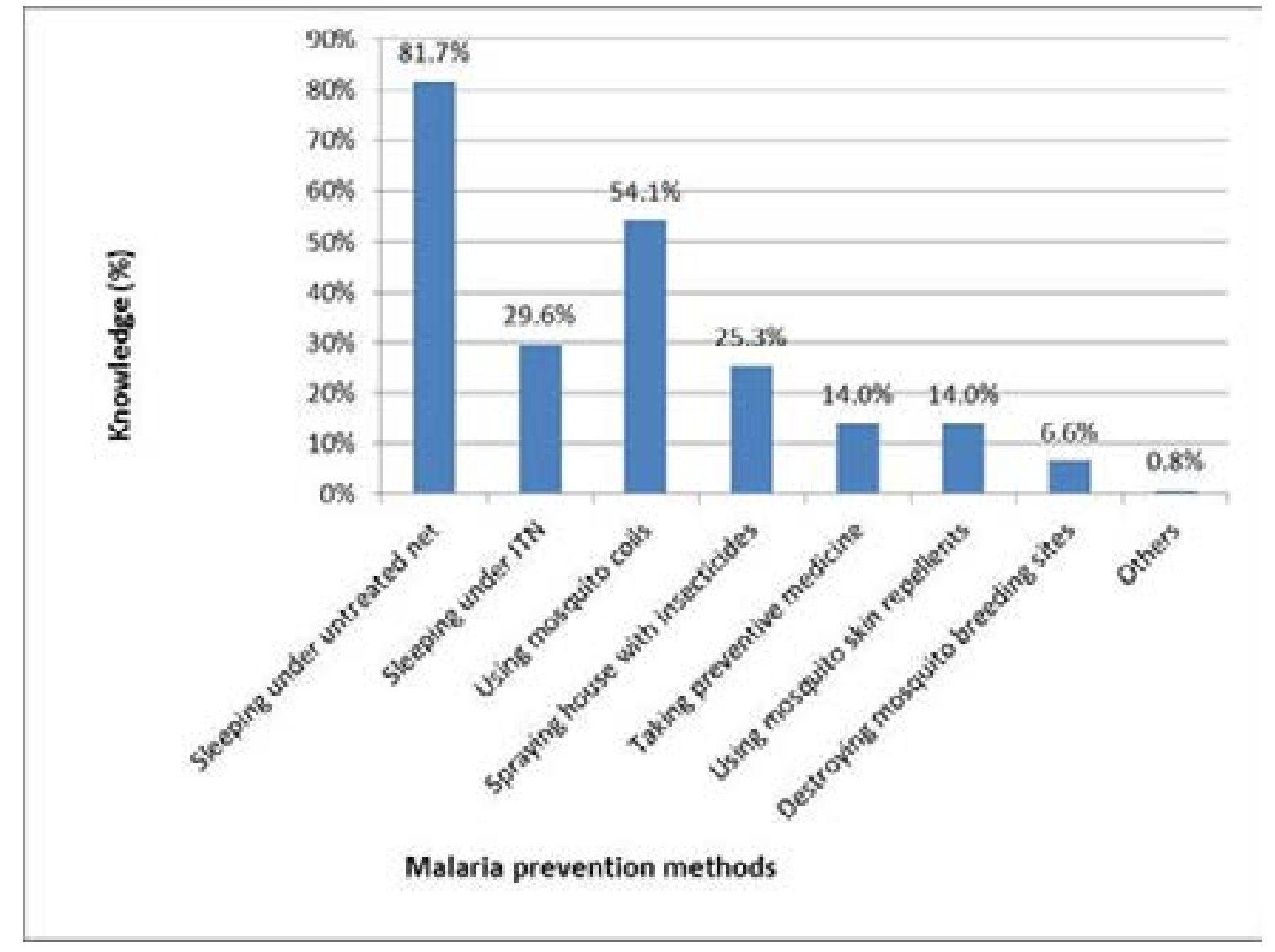

From the assessment score, the majority of participants vention methods were age $\left(\chi^{2}=32.1 ; \mathrm{p}<0.01\right)$, em $(64.6 \%)$ had low knowledge on malaria prevention ployment status $\left(\chi^{2}=18.1 ; \mathrm{p}<0.01\right)$, education $(\chi 2=$ methods, with the rest having no $(32.5 \%)$ or medium $20.3 ; \mathrm{p}=0.01)$, income $\left(\chi^{2}=14.5 ; \mathrm{p}=0.01\right)$ and having $(2.9 \%)$ knowledge. None of the participants had high heard malaria message in the previous 12 months $(\chi 2=$ knowledge on malaria prevention methods. The factors 92.3; $\mathrm{p}<0.01$ ) (Table 2). found to be associated with knowledge on malaria pre- 
Table 2 Factors associated with knowledge on malaria prevention methods

\begin{tabular}{|c|c|c|c|c|c|c|}
\hline Variable & Category & $\begin{array}{l}\begin{array}{l}\text { No } \\
\text { Knowledge } \\
\text { (score 0) }\end{array} \\
\text { n (\%) } \\
\end{array}$ & $\begin{array}{l}\text { Low } \\
\text { Knowledge } \\
\text { (score 1- 3) } \\
\text { n (\%) } \\
\end{array}$ & $\begin{array}{l}\text { Medium } \\
\text { Knowledge } \\
\text { (score 4-6) } \\
\text { n (\%) } \\
\end{array}$ & $\begin{array}{l}\text { Chi } \\
\text { square } \\
\left(\chi^{2}\right)\end{array}$ & $\begin{array}{l}P \\
\text { value }\end{array}$ \\
\hline \multirow{4}{*}{ Age } & $18-24$ & $16(20.0)$ & $62(77.5)$ & $2(2.5)$ & 32.1 & $0.00 *$ \\
\hline & $25-34$ & $26(20.5)$ & $96(75.6)$ & $5(3.9)$ & & \\
\hline & $35-44$ & $35(46.1)$ & $40(52.6)$ & $1(1.3)$ & & \\
\hline & $45+$ & $45(48.4)$ & $45(48.4)$ & $3(3.2)$ & & \\
\hline \multirow[t]{2}{*}{ Gender } & Male & $45(36.9)$ & $74(60.7)$ & $3(2.46)$ & 1.7 & 0.43 \\
\hline & Female & $77(30.3)$ & $169(66.5)$ & $8(64.6)$ & & \\
\hline \multirow{6}{*}{$\begin{array}{l}\text { Employment } \\
\text { status } \\
\text { Highest level of } \\
\text { education }\end{array}$} & Unemployed & $10(13.5)$ & $59(79.7)$ & $5(6.8)$ & 18.1 & $0.00^{*}$ \\
\hline & Employed & $112(37.1)$ & $184(60.9)$ & $6(2.0)$ & & \\
\hline & $\begin{array}{l}\text { None } \\
\text { Primary }\end{array}$ & $22(43.1)$ & $28(54.9)$ & 1(1.9) & 20.3 & $0.01^{*}$ \\
\hline & $\begin{array}{l}\text { Primary } \\
\text { Secondary } \\
\text { (ordinary } \\
\text { level) }\end{array}$ & $\begin{array}{l}47(27.7) \\
40(34.5)\end{array}$ & $\begin{array}{l}120(70.6) \\
72(62.1)\end{array}$ & $\begin{array}{l}3(1.8) \\
4(3.5)\end{array}$ & & \\
\hline & $\begin{array}{l}\text { Secondary } \\
\text { (advanced) } \\
\text { level }\end{array}$ & $10(32.3)$ & $20(64.5)$ & $1(3.2)$ & & \\
\hline & $\begin{array}{l}\text { Tertiary / } \\
\text { university }\end{array}$ & $3(37.5)$ & $3(37.5)$ & $2(25.0)$ & & \\
\hline \multirow{4}{*}{$\begin{array}{l}\text { Average } \\
\text { household } \\
\text { monthly income } \\
\text { (US dollars) } \\
\text { Household size }\end{array}$} & $<20$ & $54(43.9)$ & $65(52.9)$ & $4(3.3)$ & 14.5 & $0.01 *$ \\
\hline & $20-60$ & $55(29.7)$ & $126(68.1)$ & $4(2.16)$ & & \\
\hline & $>60$ & $13(19.1)$ & $52(76.5)$ & $3(4.4)$ & & \\
\hline & $\begin{array}{l}1-3 \\
4-6 \\
\geq 7\end{array}$ & $\begin{array}{l}32(27.4) \\
70(36.8) \\
20(29.0)\end{array}$ & $\begin{array}{l}80(68.4) \\
117(61.6) \\
46(66.7)\end{array}$ & $\begin{array}{l}5(4.3) \\
3(1.58) \\
3(4.4)\end{array}$ & 5.3 & 0.26 \\
\hline $\begin{array}{l}\text { Heard malaria } \\
\text { message in } \\
\text { previous } 12 \\
\text { months }\end{array}$ & $\begin{array}{l}\text { Yes } \\
\text { No }\end{array}$ & $\begin{array}{l}26(12.3) \\
96(58.2)\end{array}$ & $\begin{array}{l}174(82.5) \\
69(41.8)\end{array}$ & $\begin{array}{l}11(5.2) \\
0(0.0)\end{array}$ & 92.3 & $0.00 *$ \\
\hline
\end{tabular}

* Statistically significant at $\mathrm{p}<0.05$

The key informants revealed that although the com- know such practices would help their families". Village leader. munity was aware of malaria prevention methods such

as sleeping under mosquito nets, many families could not afford to implement these measures in their households:

\section{Practices on malaria prevention}

Households that had at least one mosquito net for use in the prevention of malaria were $45.5 \%$, with the mean "Basing on the income of people in this village, very few can afford number of nets being 2.11 (inter quartile range, IQR to prevent malaria because they do not have money to buy mosqui- 1-3) compared to the mean household size of 4.69 to nets or screens for their windows and ventilators even when they (IQR 3-6). The proportion of population who slept under a mosquito net the night before the survey was CI 0.27- 0.66). Participants who were employed were $28.4 \%$ compared to $43.3 \%$ among children under 5 more likely to report having a mosquito net in their years of age. There was a positive correlation between households compared to those who were unemployed household size and number of mosquito nets owned (APRR 1.2, CI $1.01-1.53$ ). Participants whose house(Spearman's correlation coefficient $=0.405, \mathrm{p}<0.01)$. holds had an average monthly income between $20-60$ Participants aged 35-44 years were less likely to report US dollars were more likely to report having a mosquito having a mosquito net in their household compared net in their households compared to those earning less to those aged 18-24 years (Adjusted Prevalence Rate than 20 dollars (APRR 1.5, CI $1.05-2.03$ ). Similarly, Ratio - APRR 0.7, Confidence Interval - CI 0.51 - participants whose households had an average monthly $0.92)$. Similarly, participants aged 45 or older were less income above 60 US dollars were more likely to report likely to report having a mosquito net in their house- having a mosquito net in their households compared to hold compared to those aged 18-24 years (APRR 0.4, those earning less than 20 dollars (APRR 2.1, CI 1.47 2.91) (Table 3).

\begin{tabular}{|c|c|c|c|c|c|c|}
\hline \multirow[t]{2}{*}{ Variable } & \multirow[t]{2}{*}{ Category } & \multicolumn{2}{|c|}{$\begin{array}{c}\text { Ownership } \\
\text { net } \\
\mathbf{N}=376\end{array}$} & \multirow[t]{2}{*}{$\begin{array}{l}\text { Crude PRR^ } \\
\left(95 \% \mathbf{C I}^{\wedge \wedge}\right)\end{array}$} & \multirow[t]{2}{*}{$\begin{array}{l}\text { Adjusted PRR } \\
\text { (95\% CI) }\end{array}$} & \multirow[t]{2}{*}{ p-value } \\
\hline & & $\begin{array}{c}\text { No } \\
\mathbf{n}=205\end{array}$ & $\begin{array}{c}\text { Yes } \\
\mathrm{n}=171\end{array}$ & & & \\
\hline \multirow[t]{2}{*}{ Gender } & Male & 78 & 44 & Ref & Ref & \\
\hline & Female & 127 & 127 & $1.4(1.06-1.81)^{*}$ & $1.3(0.99-1.62)$ & 0.06 \\
\hline \multirow[t]{4}{*}{ Age } & $18-24$ & 34 & 46 & Ref & Ref & \\
\hline & $25-34$ & 52 & 75 & $1.0(0.81-1.30)$ & $1.0(0.79-1.22)$ & 0.89 \\
\hline & $35-44$ & 48 & 28 & $0.6(0.45-0.91)^{*}$ & $0.7(0.51-0.92)^{*}$ & 0.01 \\
\hline & $45+$ & 71 & 22 & $0.4(0.27-0.62)^{*}$ & $0.4(0.27-0.66)^{*}$ & 0.00 \\
\hline \multirow{4}{*}{$\begin{array}{l}\text { Highest level } \\
\text { of educational }\end{array}$} & None & 32 & 19 & Ref & Ref & \\
\hline & Primary & 94 & 76 & $1.2(0.81-1.78)$ & $0.9(0.67-1.26)$ & 0.61 \\
\hline & Ordinary level & 56 & 60 & $1.4(0.93-2.07)$ & $1.0(0.71-1.31)$ & 0.84 \\
\hline & $\begin{array}{l}\text { Advanced } \\
\text { level and } \\
\text { tertiary }\end{array}$ & 23 & 16 & & $0.8(0.52-1.22)$ & 0.29 \\
\hline \multirow{2}{*}{$\begin{array}{l}\text { Employment } \\
\text { status }\end{array}$} & Unemployed & 127 & 82 & $\begin{array}{c}1.1(0.00-1.03) \\
\text { Ref }\end{array}$ & Ref & \\
\hline & Employed & 78 & 89 & $1.4(1.09-1.69)^{*}$ & $1.2(1.01-1.53) *$ & 0.04 \\
\hline \multirow{3}{*}{$\begin{array}{l}\text { Average } \\
\text { monthly } \\
\text { household } \\
\text { income (US } \\
\text { dollars) }\end{array}$} & $<20$ & 87 & 36 & Ref & Ref & \\
\hline & $20-60$ & 93 & 92 & $1.7(1.25-2.32)^{*}$ & $1.5(1.05-2.03) *$ & 0.03 \\
\hline & $>60$ & 25 & 43 & $2.2(1.55-3.00)^{*}$ & $2.1(1.47-2.91)^{*}$ & 0.00 \\
\hline
\end{tabular}

$\wedge \mathrm{PRR}$ - Prevalence rate ratio

$\wedge \wedge \mathrm{CI}$ - Confidence Interval

* Statistically significant at $95 \%$ confidence interval

Key informant interviews revealed that the communi- "We received mosquito nets from Government. However, the) ties had previously received support from the Govern- were given to only bouseholds with cbildren under 5 years and ment in form of ITNs. However, these were not suffi- pregnant women but still, not all households that had children or cient as noted below: pregnant women received these nets". Health worker. 
Although it was generally appreciated that use of ITNs by household members. Only $2.1 \%$ houses had complaved a big role in the prevention of malaria, some of plete mosquito proofing in windows and ventilators to the challenges faced by the community in using them prevent mosquito entry. Stagnating water was found were poverty and large family size:

"Most families in this village have many members therefore based on this fact, they cannot buy insecticide treated nets for each person in the family." Village leader.

around $17.6 \%$ of the houses while vessels that could potentially hold water for mosquito breeding were found in $37.2 \%$ households (Table 4). In addition to the stagnant water in compounds, it was established that numerous persistent pools of water in the community existed that could be used by mosquitoes for breeding: "There are very many mosquito breeding places in this area especially those resulting from excavation of clay for brick making. These breeding sites greatly contribute to the many cases of malaria in our community." CHW.

In $42.8 \%$ of households, overgrown vegetation was nets and mainly use those that were provided by the government. Some families cannot even afford to buy drugs when members bave malaria in addition to not being able to buy screening for their windows and ventilators to prevent mosquitoes entering their houses." Health worker.

Only $0.5 \%$ of the participants' houses had undergone found within 5 meters of house. Among households IRS in the previous 12 months and this had been done that opened the windows on their houses $(86.2 \%)$, near-

ly half $(47.3 \%)$ closed them after $6.00 \mathrm{pm}$ (Table 4$)$.

\section{Table 4 Malaria prevention practices and risk factors at households}

\section{Variable}

Presence of at least one mosquito net

Used indoor residual spraying in previous 12 months

Presence of mosquito proofing in windows and$$
\text { ventilators }
$$

Presence of stagnant water in compound

Presence of vessels around house that can potentially

hold water for mosquito breeding

Time of closing windows on houses

$$
\begin{aligned}
& \text { Before } 6 \mathrm{pm} \\
& \text { After } 6 \mathrm{pm}
\end{aligned}
$$$$
\text { Not applicable }
$$

Presence of overgrown vegetation within 5 meters of

house

\begin{tabular}{cc}
$\mathbf{N}=\mathbf{3 7 6}$ & Percentage (\%) \\
\hline 171 & 45.5 \\
2 & 0.5 \\
8 & 2.1 \\
& \\
66 & 17.6 \\
140 & 37.2 \\
& \\
146 & \\
178 & 38.8 \\
52 & 47.3 \\
161 & 13.8 \\
& 42.8
\end{tabular}

\section{Health seeking practices} Among the participants, $30.6 \%$ had children under 5 having no money $(23.5 \%)$, and waiting for the child's years in their households who had had a fever 2 weeks parent (11.8\%). Most participants (62.2\%) had travelled prior to data collection. Among these, $85.2 \%$ sought between $1-4$ kilometers to seek treatment when chiltreatment from various sources, the main ones be- dren in their household were sick.

ing Government health facilities (59.1\%), community

health workers $(33.7 \%)$ and private facilities $(21.4 \%)$. The rest travelled less than 1 kilometer $(23.5 \%)$ or more Treatment was first sought mainly from government fa- than 5 kilometers $(9.2 \%)$. The long distances that the cilities $(53.1 \%)$. Only $29.6 \%$ of the households sought community had to travel to seek healthcare was a signiftreatment for the sick children on the very day the fever icant challenge:

began. The rest sought treatment $1-3$ days $(61.2 \%)$ "One of the main challenges we face in seeking health services or more than 3 days $(9.2 \%)$ after onset of the fever. is the distance we have to cover to get to bealth facilities. Due to Among those who did not seek treatment, the main having few Government health facilities, people have to travel very long distances to get treatment. Families therefore spend a lot of money on transportation alone." Village leader.

Majority of participants $62.5 \%$ were aware of the existence of community health workers in form of village health teams (VHTs) in their respective areas who distributed malaria medicines. However, among these, $62.7 \%$ did not know whether the VHTs had malari medicine available at the time while only $9.7 \%$ confirmed existence of the medicine. The number of VHTs distributing malaria medicine in the community was found to be insufficient:

"We have only 4 Government trained LHTs for the whole vitlage. However, it is only 2 of these volunteers who were given malaria drugs for use by children when sick. Due to the many malaria cases among children, this medicine is usually used up in a short time leaving no medicine with these community healt workers for long periods". Village leader.

\section{Discussion}

The study established that knowledge on malaria prevention methods was low. However, participants were specifically highly aware of sleeping under mosquito nets to prevent malaria. High knowledge on mosquito nets can be attributed to the Ministry of Health's extensive campaign on increasing awareness and use of ITNs in recent years, including free distribution to vulnerable groups of children and pregnant women as established by this study. However, beyond the ITNs provided by the Government, many families could not afford to buy such nets which directly relates to the low income levels in rural areas in Uganda as established by this and other studies ${ }^{16,17}$. Poverty not only affected use of malaria prevention methods in this study but also health seeking behaviours which has been documented in other studies $^{18,19}$. Since poverty remains high in rural areas of Uganda, the Government's strategy of free distribution of ITNs is likely to greatly benefit such communities. However, some studies conducted in other parts of Africa have shown misuse of received nets including being used for fishing ${ }^{20,21}$. Therefore, an all-encompassing approach including health education and targeting other malaria prevention methods is recommended.

Knowledge on malaria prevention methods was associated with age, employment status, education, income and having heard malaria message in the previous 12 months. People who are educated are expected to have had more exposure to malaria prevention methods compared to those who are not ${ }^{22}$. Since education is a contributing factor to employment hence income ${ }^{23}$, the association of these factors to knowledge on malaria is justified. The strong association between knowledge on malaria and having heard malaria message is an indication that increased publicity could contribute towards mproving malaria prevention practices in Uganda and beyond ${ }^{24}$

With less than half of the households owning at least one mosquito net, this most advocated method of maaria prevention was being underutilized. However, it is possible that some participants may have under reported the nets their households had in anticipation of being given ITNs if they had a few or none. It was evident in this study that households gave priority to children under 5 years of age regarding sleeping under mosquito nets, a category most affected by malaria ${ }^{1}$. Indeed, $43.3 \%$ of children under 5 years of age slept under mosquito net the night before the survey compared to $28.4 \%$ among the general population. The estimated number of households owning at least one ITN nationally is $60 \%$, with an average of 1.3 ITNs $^{5}$. The positive correlation between household size and number of nets owned (Spearman's correlation coefficient $=0.405, \mathrm{p}$ $<0.001$ ) could be attributed to households with more children having received more nets from the Government.

However, with the mean number of nets being 2 compared to the mean household size of 5 , the available nets among households were clearly insufficient for the members. Ownership of nets increased with household income as established by other studies ${ }^{25,26}$. This finding is logical as nets are costly and may not be affordable by families with low income. Indeed, participants who were employed and had an income were more likely to own a net in their household as established by this study. The negative association between ownership of nets and participants who were above 34 years could be due to such households having fewer children hence receiving less free nets from the Government. Indeed, nets were provided to households with children under 5 years and/or pregnant women. The current universal coverage campaign by the Ministry of Health where one net is to be given to every two people in a household is likely to benefit all age groups. In this campaign, an estimated 21 million LLINs are to be distributed countrywide ${ }^{27}$.

Besides mosquito nets, there was low knowledge and utilization of other malaria prevention methods includ- 
ing IRS which is a key national and global strategy ${ }^{7,12}$. Wakiso district in central Uganda where this study was conducted was not among the areas where IRS was implemented by the Government which targeted mainly the northern region of the country ${ }^{6}$. In addition, the use of IRS has been found to have several challenges elsewhere including insecticide smell, mess left by the sprayers, inconvenience of removing household items from houses before spraying, increased prevalence of other insects, perceived ineffectiveness and side effects ${ }^{28,29,30}$. Installing proofing in windows and ventilators of houses was also underutilized as has been found in a related study ${ }^{31}$. Although proofing of windows, ventilators and open eaves has historically been used to prevent entry of mosquitoes in houses, the method has been ignored in many communities ${ }^{32}$. In addition to promotion of use of ITNs and IRS, advocating the use of other malaria prevention methods is important in reducing the burden of the disease in endemic countries. Indeed, the integrated approach to malaria prevention promoted in the study community after conducting this survey had immediate benefits such as reduced presence of mosquitoes in houses ${ }^{15}$. It is planned that the long term public health impact of the integrated approach in the study community will be assessed more than 2 years after implementing the project.

This study re-emphasizes the high utilisation of Government health facilities and community health workers in rural communities for the treatment of malaria among children under 5 years of age. However, the challenges of accessing these services established in this study included long distance to facilities, insufficient number of VHTs and stock-out of drugs among them. Similar challenges affecting utilisation of health services have been found in other studies carried out in Uganda and beyond ${ }^{33,34}$. These health system challenges greatly affect health outcomes particularly in rural communities which are most at need of health Therefore to improve the health of rural populations, concerned authorities such as ministries responsible for health need to address these challenges.

\section{Limitations}

A major limitation of this study was some of the malaria prevention practices such as use of mosquito net and IRS were reported as they could not be observed. Nevertheless, for the malaria prevention methods that could be seen including mosquito proofing in windows and ventilators, these were observed with guidance of observational checklist which is indeed a strength of he study. Another limitation is that the study was conducted in only 2 villages where the pilot project was to be implemented hence a relatively small sample size. This may have affected some statistical tests, and the results may not be generalised to a wider geographical area. Nevertheless, the qualitative data suitably supplemented the quantitative one and the findings can be used to inform future studies.

\section{Conclusion}

Besides mosquito nets, knowledge and practices on other malaria prevention methods was low in this study. There is potential to improve practices of malaria prevention by targeting other methods beyond ITNs, such as installing proofing in windows and ventilators. The integrated approach to malaria prevention which advocates the use of several malaria prevention methods in holistic manner should be explored for this purpose.

\section{Competing interests}

The authors declare that they have no competing interests.

\section{Acknowledgements}

We thank the Welsh Government under the Wales4A frica Health Links Grant Scheme 2011-12 for funding the malaria project. This investigation also received financial support from TDR, the Special Programme for Research and Training in Tropical Diseases, co-sponsored by UNICEF, UNDP, the World Bank and WHO. Our appreciation also goes to the entire project team (UK and Uganda), village leaders, mobilizers, local authorities, research assistants and community for their contribution towards the study.

\section{References}

1. WHO. World Malaria Report 2013. 2013. Geneva. 2. UBOS - Uganda Bureau of Statistics. Uganda Malaria Indicator Survey 2009. 2010. Kampala, Uganda. 3. WHO. World Malaria Report 2012. 2012. Geneva. 4. Orem JN, Kirigia JM, Azairwe R, Kasirye I, Walker O. Impact of malaria morbidity on gross domestic product in Uganda. Int Arch Med 2012; 5(1): 12

5. UBOS - Uganda Bureau of Statistics. Uganda Demographic and Health Survey 2011. 2012. UBOS and Calverton, Maryland: ICF International Inc.

6. Yeka A, Gasasira A, Mpimbaza A, Achan J, Nankabirwa J, Nsobya $S$ et al. Malaria in Uganda: challenges to control on the long road to elimination: I. Epidemiology and curce

121(3):184-195

7. MOH - Ministry of Health, Uganda. Health Sector Strategic Plan III 2010/11-2014/15. 2010. Kampala Uganda.

8. Walker K, Lynch M. Contributions of Anopheles larval control to malaria suppression in tropical Africa: review of achievements and potential. Med Vet Entomol 2007; 21(1): 2-21.

9. CDC. Anopheles mosquitoes. Division of parasitic diseases. 2008. http://www.cdc.gov/malaria/biology/ mosquito/ [accessed on 5th August 2009]

10. Ng'ang'a PN, Shililu J, Jayasinghe G, Kimani $V$ Kabutha C, Kabuage L, Kabiru E, Githure J, Mutero C. Malaria vector control practices in an irrigated rice agro-ecosystem in central Kenya and implications for malaria control. Malar J 2008; 7: 146

11. Kiwanuka S, Ekirapa E, Pc man $\mathrm{MH}$, Peters D et al . Access to and utilization of health services for the poor in Uganda: a systematic review of available evidence. Trans $\mathrm{R}$ Soc Trop Med Hys 2008; 102(11): 1067-1074.

12. WHO. Indoor residual spraying. Use of indoor residual spraying for scaling up global malaria control and elimination. 2006. Global Malaria Programme.

13. Gobena T, Berhane Y, Worku A. Women's knowledge and perceptions of malaria and use of malaria vector control interventions in Kersa, Eastern Ethiopia. Glob Health Action 2013; 6: 20461.

14. Keiser J, Utzinger J, Caldas de Castro M, Smith TA Tanner M, Singer BH. Urbanization in sub-saharan A rica and implication for malaria control. Am J Trop Med Hyg 2004;71(2 Suppl): 118-127.

15. Musoke D, Karani G, Ssempebwa JC, Musoke MB. Integrated approach to malaria prevention at household level in Uganda: experiences from a pilot project. Malar J 2013; 12: 327 .

16. Mbonye AK, Neema S, Magnussen P. Preventing malaria in preonancy implications in Mukono district, Uganda. Health Policy Plan 2006; 21(1): 17-26.

17. Welch K, Fuster M. Barriers in access to insecticide-treated bednets for malaria prevention: an analysis of Cambodian DHS data. J Vector Borne Dis 2012; 49(1) 1-7.

18. Tumwesigire S, Watson S. Health seeking behavio by families of children suspected to have malaria in $\mathrm{Ka}$ bale: Uganda. Health Sci 2002; 2(3): 94-98.

19. Das A, Das Gupta RK, Friedman J, Pradhan MM, Mohapatra CC, Sandhibigraha D. Community percep- tions on malaria and care-seeking practices in endemic Indian settings: policy implications for the malaria control programme. Malar J 2013; 12: 39 .

20. Minakawa N, Dida GO, Sonye GO, Futami K, Kaneko S. Unforeseen misuses of bed nets in fishing villages along Lake Victoria. Malar J 2008; 7: 165.

21. Hopkin M. The big push. Nature 2008; 451: 10471049

22. Akinleye SO, Ajayi IO. Knowledge of malaria and preventive measures among pregnant women attending antenatal clinics in a rural local government area in Southwestern Nigeria. World Health Popul 2011; 12(3): 13-22.

23. Gregorio JD, Lee J. Education and Income Inequality: New Evidence From Cross-Country Data. Review of Income and Wealth 2002, 48: 395-416.

24. Rhee M, Sissoko M, Perry S, Dicko A, McFarland W, Doumbo O. Malaria prevention practices in Mopti region, Mali. East Afr Med J 2005; 82(8): 396-402.

25. Kaliyaperumal K, Mengistie E, Dagnew Z, Deboch B. Examining household possession and willingness to pay for the retreatment of ITNs with insecticides among local residences in a malaria endemic area. East Afr J Public Health 2010; 7(4):305-310

26. Biswas AK, HutinYJ, Ramakrishnan R, Patra B, Gupte MD. Increased financial accessibility and targeted education messages could increase ownership and use of mosquito nets in Purulia District, West Bengal, India. Trans R Soc Trop Med Hyg 2010; 104(6): 423428.

27. MOH - Ministry of Health, Uganda. Distribution of long lasting treated mosquito nets. 2014. Kampala, Uganda. http://health.go.ug/mohweb/?p=1350 [accessed on 25th January 2014]

28. Rodriguez AD, Penilla RP, Rodriguez MH, Hemingway J, Trejo A, Hernandez-Avila JE. Acceptability and perceived side effects of insecticide indoor residual spraying under different resistance management strategies. Salud Publica Mex 2006; 48: 317-324.

29. Govere J, Durrheim D, la Grange K, Mabuza A, Booman M. Community knowledge and perceptions about malaria and practices influencing malaria control in Mpumalanga Province, South Africa. S Afr Med J 2000; 90(6): 611-616.

30. Kaufman MR, Rweyemamu D, Koenker H, Macha J. "My children and I will no longer suffer from malaria": a qualitative study of the acceptance and rejection of indoor residual spraying to prevent malaria in Tanzania. Malar J 2012, 11: 220.

31. Musoke D, Musoke MB, Nsubuga W. Factors associated with prevention of malaria and other diseases 
transmitted by mosquitoes at household level in Wakiso district, Uganda. Journal of Environmental Health Research 2013; 13(1): 59-67.

32. Lindsay SW, Emerson PM, Charlwood JD. Reducing malaria transmission by mosquito-proofing homes. Trends Parasitol 2002, 18(11): 510-514.

33. Kiguli J, Ekirapa-Kiracho E, Okui O, Mutebi A, Macgregor H, Pariyo GW. Increasing access to quality health care for the poor: Community perceptions on quality care in Uganda.Patient Prefer Adherence 2009; 3: 77-85.

34. Smith N, Obala A, Simiyu C, Menya D, Khwa-Otsyula B, O'Meara WP. Accessibility, availability and affordability of anti-malarials in a rural district in Kenya after implementation of a national subsidy scheme. $\mathrm{Ma}$ lar J 2011; 10: 316. 